\title{
Conjunctive paraconsistency
}

\author{
Franca d'Agostini ${ }^{1}$
}

Received: 31 October 2017 / Accepted: 20 February 2021 / Published online: 31 March 2021

(c) The Author(s) 2021

\begin{abstract}
This article is a preliminary presentation of conjunctive paraconsistency, the claim that there might be non-explosive true contradictions, but contradictory propositions cannot be considered separately true. In case of true ' $p$ and not p', the conjuncts must be held untrue, Simplification fails. The conjunctive approach is dual to nonadjunctive conceptions of inconsistency, informed by the idea that there might be cases in which a proposition is true and its negation is true too, but the conjunction is untrue, Adjunction fails. While non-adjunctivism is a well-known option, the other view is not so much studied nowadays, but it was not unknown in the tradition, and there are some positive suggestions, in recent literature, that the position is plausible and deserves to be developed. The article compares conjunctivism, nonadjunctivism and dialetheism, then focuses on some possible justifications, costs and benefits of the conjunctive view.
\end{abstract}

Keywords Conjunction $\cdot$ Dialetheism $\cdot$ Non-adjunctivism $\cdot$ Paradoxes $\cdot$ Truth

A conjunctive conception of paraconsistency consists of claiming that there can be non-explosive contradictions but contradictories cannot be separately true. ${ }^{1}$ So the 'and' that joins ' $p$ and not p' in case of true contradiction is not simplifiable: 'p' and 'not p', separately taken, are untrue. The aim of the article is to present a version

\footnotetext{
${ }^{1}$ The expression conjunctive paraconsistency is adopted by Ripley (2015: pp. 771-772) to mean the property of a consequence relation so that $\mathrm{A} \wedge \neg \mathrm{A} \vDash \mathrm{B}$ does not hold (for wffs $\mathrm{A}, \mathrm{B} \in \mathrm{L}$ ), as opposed to collective paraconsistency, whereby A, $\neg \mathrm{A} \vDash \mathrm{B}$ does not hold (see also Barrio \& Da Re, 2018). The term means here a slightly different position, as 'conjunctive' is not opposed to 'collective', but to 'distributed'. I keep the term because (as in Ripley's stipulation) it seems expressive of the duality with NonAdjunctivism (failure of $\mathrm{A}, \neg \mathrm{A}=\mathrm{B}$ and acceptance of $\mathrm{A} \wedge \neg \mathrm{A} / \mathrm{B}$ ) and an analogy with dialetheism (failure of both) which the article intends to stress. One might also speak of fusional paraconsistency, as the postulated conjunction is similar to fusion in relevance logic (see especially Mares, 2012), but 'fusion' is sometimes used with a different meaning (see Fine, 2012, 2017; Priest, 2015; Estrada Gonzales, 2017), and 'fusional' may generate equivocation ('fusionism' is sometimes used to denote a rightwing political position, which is not, evidently, what is intended here).
}

Franca d'Agostini

franca.dagostini@unimi.it

1 Universita Degli Studi Di Milano, Milan, Italy 
of this view, which is not so much studied in the current literature. It is suggested that if one wants to acknowledge the existence of true contradictions (or to admit the possibility of contradictions) there could be reasons to adopt such a perspective. More specifically, the article shows that conjunctivism in paraconsistency relies on a conception of truth that preserves the exclusion constraint classically involved in the use of the concept (whereby if ' $p$ ' is true 'not p' cannot be true), while acknowledging the possibility of true state descriptions of the form ' $p$ and not $p$ '. That such a conception is to be held preferable to other options will not be dealt with here. The aim is to show that the conjunctive view is plausible, and its consequences are interesting for anyone who is concerned with the notion of 'true contradiction'.

In the first section, three ways of interpreting the conjunction problem (the joined subsistence of incompatibles in case of true contradictions) are presented: dialetheism, non-adjunctivism and conjunctivism. Three examples of a conjunctive treatment of paradoxes are suggested in the second section; in the third section some objections and open problems are explored, and the last section explains the underlying conception of truth. The development of a consequent semantics will be the concern of another paper, though some anticipations are given in the last section (Sect. 4.3).

\section{Three 'and'}

A contradiction is a contradictory object. It is the joined subsistence of what in principle cannot jointly subsist. If we accept that there are true contradictions, we are committed to explain — among other things—what we mean by 'joined subsistence'. As 'and' normally stands for joined subsistence (joined truth), one may think there is something special in the postulated 'and'. In the literature about inconsistency the conjunction problem is treated by three basic positions: dialetheism, non-adjunctivism and conjunctivism. They all accept that there can be true contradictions but differ in the interpretation of the 'and' joining 'p' and 'not p'. For dialetheists (see for the most well-known versions Priest $1987^{2}$, 2006, Priest et al., 2004; Beall, 2009), it is a perfectly normal 'and', classically defined by the Conjunction Thesis:

\section{$C T:\langle p$ and $q\rangle$ is true iff $\langle p\rangle$ is true and $\langle q\rangle$ is true. $^{2}$}

The acceptance of this classical bi-conditional implies that the two basic rules of Simplification (from left to right), and Adjunction (from right to left) both hold, so if ' $p$ and not p' is true, the two contradictories are both separately and jointly true. For non-adjunctivists, there are cases in which 'p' and 'not p' are acceptable, but in those cases the conjunction ' $p$ and not p' is untrue, Adjunction fails. Non-Adjunctivism dates back to Jaśkowski (1948, 1999), and has been developed by many authors,

\footnotetext{
${ }^{2}$ It is the terminology of Rodriguez-Pereyra (2006), who points out the distinctive features of 'and' in metaphysics (with focus on the failure of Simplification: see here Sect. 3.2). As to quotations, inverted commas are used for mention, the angle brackets for truthbearers, and the truthmaker is without any quotation mark. For instance: if $<p>$ is true, the sentence ' $p$ ' is to be accepted, as it is made true by the fact that $\mathrm{p}$.
} 
in different ways. The third position is symmetrically opposed to non-adjunctivism, and it is the idea that there can be non-explosive true contradictions of conjunctive form, so some ' $p$ and not p' can be true, but in this case, 'p' and 'not p' cannot be said separately true: the left to right direction of CT does not hold; Simplification fails.

While dialetheism and non-adjunctivism are well-known approaches to paraconsistency, there is no clear and definite position of the third kind in recent literature ${ }^{3}$ but there are reasons to believe it was not unknown in the tradition. ${ }^{4}$

\subsection{Asymmetries}

In the account here proposed, the three positions share the basic dialetheic postulate, that:

\section{D: there are some true contradictions}

But they differ in saying what is meant by D. Conjunctivists and dialetheists believe a true contradiction has a conjunctive form, so $\mathrm{D}$ implies:

\section{D1: there are some true propositions of the form ' $p$ and not $p$ '}

This is namely what non-adjunctivists do not accept: they hold there is no true conjunction of contradictories. Dialetheists also believe that:

\section{D2: there are some true propositions whose negation is true}

A dialetheia is held to be a proposition of this kind, and on the understanding that 'falsity' is the truth of negation, a true contradiction is a true and false proposition. D2 is accepted by non-adjunctivists, while conjunctivists reject it. So Non-Adjunctivism (Non-Adj) and Conjunctivism (Conj) can be seen as forms of anomalous or asymmetrical Dialetheism. The latter rejecting D2 and accepting D1, the former accepting D2 and rejecting D1.

On normal conditions, D1 and D2 are equivalent. But contradictions cannot be said to be 'normal' facts. The basic aim of Conj and Non-Adj, as dialetheically asymmetrical and reciprocally dual positions, is the will to save something of the traditional enmity between truth (the use of the concept of truth) and contradiction. In both cases, this is attempted by focusing on the conjunction (the 'joined subsistence') problem.

\footnotetext{
${ }^{3}$ Sparse hints are to be found in Beall (2006a, 2006b), d'Agostini (2008, 2014), Kabay (2010), Beall and Ficara (2014), Cobreros et al. (2015), Estrada Gonzales (2017), Ficara (2021).

${ }^{4}$ Hegel and Hegelians are alleged to be its supporters (see especially Havas, 1981, 1983; Beall \& Ficara, 2014; Ficara, 2015, 2021), and even Aristotle, to a certain extent, endorsed a similar position (a hypothesis advanced in Ramirez, 2017 and mentioned, in passing, by Priest, 2006: p. 11).
} 


\subsection{Non-adjunctivism}

The basic idea of non-adjunctive strategies is that the simultaneous being (believed or considered) true of some 'p' and 'not p' is possible, if the two propositions belong to different logical or epistemic systems, situations, or worlds, so that contradictions may occur distributively but not conjunctively (see Berto, 2007: pp. 131-150). The paradigmatic situation of Jaśkowski's discussive logic is the case of 'theses advanced by several participants in a discourse' that are 'combined into a single system' (Jaśkowski, 1948: p. 149). In Rescher and Brandom's semantics, 'p' and 'not p' might both be true, but in distinct possible worlds, and there is no world in which 'p and not p' is true (Rescher \& Brandom, 1980). Non-Adj can be justified by appealing to doxastic states, as in Lewis (1982): an ideal epistemic agent $S$ believes that $\mathrm{p}$ and believes that not $\mathrm{p}$, but does not believe ' $\mathrm{p}$ and not $\mathrm{p}$ ', and this happens because our systems of beliefs are 'broken into fragments', and 'different fragments came into action in different situations' (p. 103). A good example of nonAdjunctive treatment of contradictions is given by Varzi (2004: p. 95), building on Belnap (1977). Consider a computer programmed to answer 'yes' or 'no' to queries, and used by two different agents, of which one enters ' $p$ ' and the other enters 'not p'. The computer separately answers 'yes' to 'p?' and 'yes' to 'not $p$ ?' but 'no' to 'p and not p?'. It accepts each conjunct, but not their conjunction, Adjunction fails.

A first objection commonly addressed to non-adjunctivists is that their postulated 'and' does not seem to be an 'and', actually, so they 'change the subject': they refer to another operator, different from 'and', and maybe different from our common intuitions about 'and'. In fact, conjunction is a weird operator, it often betrays our 'common intuitions' as captured by $\mathrm{CT}^{5}$ In particular, the failure of the Adjunction rule can be justified in a variety of ways, say, by noting that a rational agent may accept each 'p' and 'q', separately, while rejecting 'p and q'. Suppose $|\mathrm{p}|=0.8$ and $|\mathrm{q}|=0.9$, and $S$ 's epistemic standard is $T p \leftrightarrow|p| \geq 0.8$; now $S$ is perfectly entitled to accept 'p' and 'q', but not 'p and q', whose value (if 'p' and ' $\mathrm{q}$ ' are independent) will be $0.72 .{ }^{6}$ To see how this solution may work in the case of presumably true contradiction, consider an example frequently mentioned by Priest $\left(1987^{2}: 100\right.$; Priest, 2006: pp. 105, 133): $\mathrm{S}$ believes that $\mathrm{p}$ and believes that $\mathrm{q}$, but she comes to know that they cannot be jointly true. As a rational agent, $\mathrm{S}$ acknowledges that her beliefs are not so sure in this case, thus, she feels entitled to accept 'p' and ' $q$ ', while accepting that at least one of them might be untrue, thus rejecting 'p and q'. Priest (2006: p. 105) believes this is a rational contradiction, but it is a controversial question. Sorensen (2003a) speaks of 'paradoxes of rationality', while Smith (2016) holds in these cases there is a certain amount of irrationality.

A second objection is that the challenge of the 'joined subsistence' is not faced but dodged by non-adjunctivists. This may be intended first as meaning that

\footnotetext{
${ }^{5}$ See Humberstone (2011: pp. 658-661), Schein (2017), Rodriguez-Pereyra (2006, 2009), Mares (2012), Read (2012: pp. 36-50).

${ }^{6}$ Generally, conflicts between conjunctive and distributed beliefs are solved in this way: typical examples are The Preface Paradox and The Lottery Paradox (Leitgeb, 2014; Sorensen, 2018a, 2018b).
} 
non-adjunctive contradictions are not 'contradictions', eventually, as they do not satisfy Aristotle's Fundamental Condition: that for a contradiction to occur, the two terms must obtain 'at the same time and under the same respect'. As Rescher and Brandom state (1980: p. 58): 'The present approach [...] dispenses entirely with any need to modify the principles of classical logic'. So that Priest and Routley comment 'This strategy has only the appearance of paraconsistency. In essence it is just a revisionist classical logic' (Priest \& Routley, 1989: p. 161).

Another way of interpreting the objection is that non-Adjunctive contradictions are 'contradictions' in a loose sense (pairs of propositions such that one is the negation of the other), but they cannot be said 'true'. The truth postulated by the nonadjunctive interpretation of $\mathrm{D}$ is transitory, or fictional, fragmented or merely possible truth. In this sense, one may contend that non-adjunctivists 'do not take the dialetheic motivation (that there are true contradictions) seriously' (Priest \& Routley, 1989: p. 162). As Jaśkowski suggests: 'it would not be correct to formulate Aristotle's principle of contradiction as "two contradictory sentences are not both true". We have namely to add: "in the same language", or "if the words occurring in those sentences have the same meaning"' (Jaśkowski, 1948: p. 144). In Jaśkowski's discussive logic, 'p' and 'not p' are only 'possibly true', or 'true in accordance with the opinion of one of the participants' (p. 149), so one would say the two propositions are contrary and not contradictories (which explains the affinity of Non-Adj with truth-value-gap or T-free logics). In the same line, one may note that Varzi's computer is 'neutral', it is not committed to alethic evaluations. So for the computer, 'p' and 'not p' are neither true nor false. Not unlike, in Lewis' picture, $\mathrm{S}$ is not aware of the inconsistency. Presumably, if she were aware, she would try to reduce the cognitive dissonance in some way, and if she could not, she would acknowledge, honestly, that she does not have a clear idea about the issue (so again, the apparent glut is in fact a gap, an epistemic lacuna).

In conclusion, one would say that in non-adjunctive cases there is, or there appears to be, a contradiction, but whether the contradiction is (can be said) true seems to be another question (see Sect. 4).

\subsection{Dialetheism}

The distinctive aspect of the dialetheic perspective is the focus on truth. In this sense, dialetheism can also be seen as the claim that the use of the concept of truth does not exclude (rather implies) the occurrence of true contradictions, and this is most frequently intended, by dialetheists, in terms of both D1 and D2. ${ }^{7}$

\footnotetext{
${ }^{7}$ In his 'Survey of the Definitions of Dialetheism', Martin (2014: pp. 225-228) lists 26 different definitions, of which nine are given in terms of D (without specification), seven in terms of D2, and four in terms of both D1 and D2. What we can see in all of them, altogether, is that D gives the minimal distinctive feature (if not the necessary and sufficient condition) of a 'dialetheic' perspective. As Priest clearly states: 'the fact that we are faced with, or even forced into operating with, information that is inconsistent, does not, of course, mean that that information is true. The view that it may be is dialetheism [...] A dialetheist is therefore a person who holds that some contradictions are true' (Priest, 2007: p. 131). This is only one of the occurrences in which Priest provides for a characterization of dialetheism, but it is particularly significant, as Priest here specifically insists on the reference to truth as distinctive character of the dialetheic view (see also Sect. 4).
} 
The Liar paradox is the best-known case advanced by dialetheists to support D2, and D1 via D2. Given the Liar's sentence ' $\mu$ ', which says: ' $\mu$ ' is not true, you will have that if ' $\mu$ ' is true then it must be untrue, and if it is untrue then it is true, so the sentence appears to be true and untrue at the same time. There are different ways of presenting the $\operatorname{argument}^{8}$; the standard way relies on the naïve truth theory, better known as the T-schema (Tarski, 1944):

$\mathrm{T}\langle\mu\rangle \leftrightarrow \mu(\mathrm{Df} . \mathrm{T})$,

which implies release:

$\mathrm{T}\langle\mu\rangle \rightarrow \mu($ Rel. $)$

And capture:

$\mu \rightarrow \mathrm{T}\langle\mu\rangle($ Capt.)

The Liar says that what she is saying is untrue, and thus we have the Inclosure Schema (Priest, 1995: pp. 147-149):

$\mathrm{T}\langle\mu\rangle \leftrightarrow \neg \mathrm{T}\langle\mu\rangle$

which by Rel. means

$\mu \leftrightarrow \neg \mu$.

The bi-conditional contradiction becomes conjunctive (i.e. $\mu \wedge \neg \mu$ ) in virtue of the Excluded Middle: from $\mu$ you draw $\neg \mu$, then $\mu \wedge \neg \mu$; from $\neg \mu$ you draw $\mu$, and hence $\mu \wedge \neg \mu$; so given $\mu \vee \neg \mu$, unquestionably: $\mu \wedge \neg \mu$.

As mentioned, that there is a contradiction (in a generic unrestricted sense of 'there being') does not mean that the contradiction is true. Dialetheists embrace the latter position: the contradiction is true, and we should accept it; if 'solving' a paradox means to eliminate the contradiction, then there is no solution (as Priest colourfully says, trying to 'solve' the Liar is 'barking up the wrong tree'). This is justified at first by considering that alternative strategies fail (the Liar revenges in a variety of ways) or imply abstract restrictions of the expressiveness of language. Besides that, if we want to have a theory of truth, we must admit that some sort of self-reference, reflexivity, or closure, is inevitable (Beall, 2009); and if we have closure, we inevitably have contradictions (or triviality, as in the case of Curry-Löb paradox). Finally, as it is well synthetized by Priest (2004: pp. 29-32), the main reason why we are so worried about contradictions is that contradictions are held to be worrying phenomena, which is deontic (vicious) circularity: we think we cannot because we think we cannot. But the developments of non-classical logic have shown that in believing

\footnotetext{
8 As well-known, there are very many different approaches or rather families of approaches to the Liar, some of them avoid the T-schema, some others do not even accept the argument (see the complex classification proposed by Scharp, 2013: pp. 23-25). Not only that, some dialetheic favoured treatments differ from Priest's as they do not appeal to the Inclosure Schema (Beall, 2014; Beall, et al., 2017, 2018). These differences are not considered here as we are interested only in dialetheism as a way of interpreting the conjunction problem.
} 
this we are wrong, as we have systems, such as LP and FDE, in which the acceptance of D1 and especially D2 is perfectly plausible.

In keeping to the T-schema, and the normal meaning of conjunction and negation, dialetheists assume that each of the two 'sides' of a dialetheia is true, and their conjunction is true too, so they are (in principle) anti-non-adjunctivist and anti-conjunctivist. ${ }^{9}$ The 'and' that joins contradictories behaves as it is intended to behave in any other occurrence. The interesting consequence is a third thesis:

\section{D3: a true contradiction is true and false}

So if ' $p$ and not p' is true, this means that ' $\operatorname{not}(\mathrm{p}$ and not $\mathrm{p})$ ' is true too. D3 is a natural consequence of $\mathrm{D} 2$, as long as one keeps to the T-schema and the standard meaning of the operators. If we have $p \wedge \neg p$, by Simpl. we have $p$ (hence $\neg \neg p$ ) and $\neg \mathrm{p}$ ( so $\neg \neg \neg \mathrm{p}$ ), which means $\neg(\mathrm{p} \wedge \neg \mathrm{p})$. The 'truth' that we ascribe to contradictions is thus double double truth. As Priest clearly explains (2002b: p. 654), if A is both true and false at a world, 'given that the conjunction behaves normally, it follows that $\mathrm{A} \wedge \neg \mathrm{A}$ is false; and so $\neg(\mathrm{A} \wedge \neg \mathrm{A})$ is true at the world as well' (the emphasis is mine). The noteworthy consequence is that the Law of Non-Contradiction (LNC) is not rejected by dialetheists, rather accepted unrestrictedly, because ' $\neg(\mathrm{p} \wedge \neg \mathrm{p})$ ' must hold for any ' $\mathrm{p}$ '.

As it has been frequently noted (see Sainsbury, 1995: pp. 150-159; Shapiro, 2004; Field, 2005, 2008; Berto, 2007, 2008; Beall, 2006a), in accepting D3 dialetheists are faced with some 'expressive' problems. One-possibly the most important-is that D3 would affect the (self-)definition of dialetheism: 'a problem with defining dialetheism as the doctrine that certain sentences are both true and false is that while a dialetheist should certainly assert [...] True $(\langle A\rangle \wedge$ False $\langle A\rangle)$ for certain A (e.g. the Liar sentence), he should deny this as well' (Field, 2005: pp. 24-27). Indeed, in general, the question of what, ultimately, dialetheists rule out remains a crucial topic of discussion. In fact, it could be seen as the crucial topic of discussion for any acceptance of D (Sect. 1.5).

\subsection{Conjunctivism}

In the version here proposed, Conj is 'a kind of dialetheism' as it consists of sharing two important dialetheic claims: that there may be true contradictions of conjunctive form (D1), and that the meaning and use of the concept of truth do not prevent (rather imply) the acceptance of true contradictions. To make things clearer, it can be useful to distinguish dialetheism (some contradiction is true) from di-aletheism (some proposition is true and its negation is true too), and dialetheias (true contradictions) from di-aletheias (true and false propositions). In this sense, one would say

\footnotetext{
${ }^{9}$ In fact, dialetheism is a well-developed and refined philosophical position, involving themes of metaphysics, epistemology, philosophy of language, social epistemology and philosophy of law, so even if D2 can be seen as dominant, as both logics favoured by dialetheists (LP and FDE) postulate truth value gluts, there are positive hints of non-adjunctive and conjunctive treatments of contradictions in the dialetheic literature.
} 
that conjunctivists favour a dialetheic but not di-aletheic theory of truth (see Sect. 4). Altogether, Conj presents 'a way of being glut-theorist' that does not strictly rival the most common dialetheic way (as defined by D) but offers a different solution to the 'joined subsistence' problem.

You may have inconsistent information in a variety of occurrences, and one of them is the case well expressed by non-adjunctivists: two different sources, separately, justify 'p' and 'not p'; you are not in the position to select (exclude) one, so you accept both, but separately. Conjunctivists can easily concede that this treatment of prima facie contradictions may make sense, but they would contend that these cases do not fall under D: 'p' and 'not p' non-adjunctively considered cannot be said to form a true contradiction, basically (as seen in Sect. 1.2) because the Aristotelian condition is not satisfied (so the case is not a contradiction), and because the 'truth' involved is only transitory or probable or possible truth (the state description is not properly true). In the conjunctive hypothesis D is to be intended in terms of D1: there can be positive cases of contradiction, so that ' $p$ and not p' is true in classical categorical sense (definitely true in any respect: Sect. 4); but they reject D2, so they assume that the two conjuncts of a true contradictory statement or proposition cannot be said true. ${ }^{10}$

In the way in which they are presented here, Non-Adj and Conj are symmetrically opposed acceptances of the Law of Non-Contradiction (LNC) in its two alethic versions, viz. the two 'Laws of Non-Dialetheia':

\section{LND1: There cannot be any true ' $p$ and not $p$ '}

And

\section{LND2: There cannot be any true ' $p$ ' whose negation is true}

Non-Adjunctivists accept LND1 and reject LND2, conjunctivists accept the latter and not the former. Thus, the basic conjunctive thesis is that:

\section{$C$ : there can be true contradictions, but there cannot be any true and false proposition.}

While for non-adjunctivists the two contradictories are not strictly 'joined' in the metaphysical sense (there is no contradictory truthmaker as such: Sect. 4.1), conjunctivists can accept the Fundamental Condition in the strongest Aristotelian meaning, whereby speaking of 'true contradiction' means to imply that there is some state (of affairs) of a conjunctive nature that works as truthmaker for ' $p$ and not p'. So they can endorse a strong form of paraconsistency.

In a possible formulation, the theory consists of three theses:

C1: there are some states (of affairs) whose state description in terms of $\langle p$ and not $p>$ is true

\footnotetext{
${ }_{10}$ As it will be specified later, in the conjunctive hypothesis negation loses its exclusionary property, while truth keeps it. So if we are willing to accept contradictions in the conjunctive form, Conj requires us to accept that 'p' does not always exclude 'not p', but maintaining that if 'p' is true then 'not p' must be held untrue (negation-exclusion is dropped, alethic exclusion is preserved: Sect. 3.1).
} 


\section{C2: the two conjuncts of a true contradiction are untrue}

Consequently:

C3: the conjunction that joins two contradictory sentences in a true contradiction is not simplifiable: that $\langle p$ and not $p\rangle$ is true does not entail that $\langle p\rangle$ is true and $\langle$ not $p\rangle$ is true.

$\mathrm{C} 1$ is a version of D1 that expresses a 'realistic' commitment to paraconsistency (there might be some contradictory states, but not any state of affairs is a contradiction). Notably, it does not imply, as such, any specific ontological restriction. Contradictory truthmakers could be physical facts, ideally captured by our sensory experience, but also non-physical, semantic, intentional facts. ${ }^{11} \mathrm{C} 2$ presents what seems the most implausible thesis of Conj, that two untrue sentences may make a conjunction true. As will be specified later, this is justified at first by the idea that the two contradictory propositions are partial state descriptions, so they are untrue as unassertable ('untrue' here means neither true nor false, which is intended to express a gap for over-determination: see Sect. 4.3). As to C3, it is a logical consequence of $\mathrm{C} 2$ and it is supported, metaphysically, by assuming that the contradictory state postulated by $\mathrm{C} 1$ consists of two inseparable parts of only one state, acting as a truthmaker for ' $\mathrm{p}$ and not p' (Sect. 3.2).

\subsection{Explosion avoided; exclusion preserved}

Many things should be specified. For now, let us consider only two noteworthy features of the conjunctive strategy.

A first consequence of accepting D1 without D2 (so admitting C3) is that it provides unusual but very simple a way of disproving the pseudo-Scotus argument (also known as ex contradictione quodlibet, or Lewis' rule, or explosion principle), which is the typical concern of paraconsistent logicians. The argument shows that accepting just one contradiction everything is proved true, so everything is contradictory. It classically needs three rules: Simplification, VIntroduction, and Disjunctive Syllogism (or Material Detachment). To block the argument, one should remove at least one of the three rules, and the most shared proposal is to remove DS (which is otherwise a problematic rule). In the conjunctive strategy, the argument immediately fails, as Simplification for contradictions does not hold (C3). ${ }^{12}$

\footnotetext{
11 Priest endorses a similar truthmaker neutrality for dialetheism. 'If something is true, there must be something that makes it so. Call this the world. If some contradictions are true, then the world must be such as to make this is the case'. As to what 'the world' is like, 'In Contradiction is in fact largely neutral [...]. Metaphysical dialetheism is simply a consequence of dialetheism plus the appropriate form of metaphysical realism and will stand or fall with this' (Priest 1987²: pp. 299, 302).

12 The same strategy can be adopted in the case mentioned by Priest to show that DS does not work in glutty cases: suppose 'p' is a dialetheia, and $\langle q\rangle$ is false; you have that $\langle p \vee q\rangle$ is true, $\langle\neg p\rangle$ is true too, but the conclusion $\langle q\rangle$ is false: DS is not truth preserving. Priest says it is a 'quasi-valid' inference, 'it is classically valid but dialetheically invalid' (Priest, 2006: p. 110). For Conj, if $\mathrm{p}$ is a dialetheia, then $\langle\mathrm{p} \wedge$ $\neg p\rangle$ is true, but 'p' and ' $\neg$ ' are separately unacceptable, and as such untrue. The second step of the argument does not hold: if $\mathrm{p}$ is a dialetheia and $\langle q\rangle$ is false, then both $\langle p \vee q\rangle^{* *}$ and $\langle\neg p\rangle$ are untrue (C2).
} 
In fact, the most successful attempt to disprove ECQ is by appeal to relevance logic, which provides semantic as well as epistemic reasons. The argument is clearly an irrelevant inference; it can be considered one of the typical paradoxes of classical entailment. As dialetheists repeat, it is irrational to assume that as soon as you acknowledge that, say, the Liar paradox is a true contradiction, you immediately imply that the Earth is not round, or God exists, or whatever (Priest, 2008: pp. 74-77). In fact, relevance logic rejects unrestricted DS, but it also admits both non-adjunctive and conjunctive versions of 'and' (Read, 2012: pp. 36-50; Mares, 2004). In particular, 'fusion' is an intensional non-simplifiable conjunction. In the situation-sensitive semantics of Mares (2012) fusion works as a 'premise binder', so that some ' $\mathrm{p}$ and q' at some inferential step does not entail 'p' (or ' $q$ ') separately. ${ }^{13}$ One may assume that the 'and' joining contradictories in the conjunctive hypothesis is of this kind, which seems to be profitable for a conjunctive interpretation of the Liar (Sect. 4.2).

A second interesting feature of Conj is that it allows us to accept D1 (that a contradiction of conjunctive form is true) without renouncing the exclusion constraint classically involved in the use of the concept of truth, whereby necessarily, if a proposition is (held) true, then its negation must be (held) untrue. Alethic Exclusion (AE) is actually the conditional version of LND2:

\section{$A E$ : if $\langle p\rangle$ is true then $\langle$ not $p\rangle$ cannot be true}

In accepting LND2 (and rejecting D2) Conj automatically preserves AE. It is important to remember that we are speaking of 'AE' (i.e. that truth implies the exclusion of falsity) and not of the 'exclusion principle' in general (sometimes also known as 'Frege-Geach principle'), whereby 'p' as such excludes 'not p'. In the conjunctive view, negation is not exclusion, what is exclusive is truth (Sect. 3.1). One may say that (as Beall, 2006a suggests) when you have a true contradiction negation is 'on holiday', it loses its property of excluding the opposite. ${ }^{14}$

The basic idea of Conj is that contradictions might occur, and might be truthfully described as such (C1), but this does not require any acceptance of falsity, or any rejection or restriction of $\mathrm{AE}$, because the two conjuncts of a true contradiction are neither true nor false (C2) and cannot be asserted separately (C3). In this way, conjunctivists may dispel at least some of the perplexities traditionally opposed to dialetheism, or to glutty truth-theorists in general. As said in Sect. 1.3, dialetheists accept almost any version of LNC (see Berto, 2008; Martin, 2015); but, in admitting D2 and hence some coincidence or overlapping of truth and falsity as a distinctive

\footnotetext{
13 One of the seminal intuitions that brought about relevance in logic is that there are illegitimate 'suppressions' in classical logic (see especially Plumwood, 1970 ca.). Not by chance, a motivation for relevance is that the inference $\mathrm{p}, \mathrm{q} \vdash \mathrm{p}$ by two applications of the deduction theorem (if $\mathrm{A} \vdash \mathrm{B}$ then $\vdash \mathrm{A}$ $\rightarrow$ B) generates the paradox $\vdash \mathrm{p} \rightarrow(\mathrm{q} \rightarrow \mathrm{p})$ (Mares \& Meyer, 2001: pp. 284-285). So there might be something wrong with suppressions, for sets of sentences (collections), as well as for conjunctive sentences: reduction is not logically innocent (see Schein, 2017).

14 For Beall this is only a possible option (a possible 'aspect' of dialetheism), as classical negation-falsity is to be preserved; but it may be appropriate for conjunctivists, who can say that thereby the exclusion task is fulfilled by truth.
} 
character of true contradictions, $\mathrm{AE}$ is necessarily dropped (the 'exclusion constraint [...] is (of course) dropped, since some sentences may be gluts', Beall, 2009: p. 18). For conjunctivists, the acceptance of D1 does not require this, one may peacefully admit that ' $p$ and not p' is to be said true, without getting rid of AE. This means that D3 is rejected too, a true contradiction is simply true, its negation is untrue. As mentioned in Sect. 1.3, dialetheism has often been discussed insofar as endorsing D3 (which is a natural consequence of D2). ${ }^{15}$ The main difficulty is possibly related to the discussive role of AE: if you state that a certain ' $p$ ' is a dialetheia, and someone does not agree with you, then you cannot disagree with her, because in your view it is true that 'p' is a dialetheia, but it is also true that it is not. Different solutions have been proposed (a notion of 'material incompatibility' is advanced by Berto, 2007: pp. 284-292, 2008). The solution that conjunctivists can provide is that there is no need to renounce (reject or restrict) AE in any form: one can perfectly accept that some contradictory state description is true, without modifying the usual notion of truth; one should simply reject Simplification in case of contradictory statements. You acknowledge that there is a contradiction, and the case is well described by ' $p$ and not p' (C1), but in virtue of AE, you exclude that there is not: the case is not describable as 'not(p and not $p)$ '. The truth that conjunctivists ascribe to ' $p$ and not p' is thus 'simple', 'unilateral' truth, they accept that every true proposition (contradictions included) is just true or true simpliciter (see Sect. 4). ${ }^{16}$

All this does not imply that Conj is to be considered as a sort of 'true dialetheism' or the best way of being glut theorist. Simply, the adoption of a conjunctive view seems to provide some new support to the idea of true contradiction, by taking into account the traditional objections concerning the notion of 'ruling out' and the exclusionary property of truth (thereby a fundamental and unmissable feature of the concept must be the rejection of falsity). A strict, orthodox dialetheist could oppose that a conjunctive position, so intended, would not be properly dialetheic, as ' $p$ and not p' behaves as if it were an atomic sentence, while the challenge is due to the double nature of the dialetheia; so again, 'the dialetheic motivation is not taken seriously'. They may have some reasons for such a claim (Sect. 3.2).

\footnotetext{
$\overline{15}$ See Berto (2007: pp. 279-316) for a synthetic presentation of the discussions.

16 The idea may have some impact on the epistemology of contradictions. Dialetheists are normally evidentialist ('one ought to accept something if there is good evidence that this is the case': Priest, 2006: p. 109). There are different accounts of evidence in epistemology, but all of them imply doxastic contrastivity and hence exclusion (in Hintikka's epistemic logic, contrastivity is the grounding feature of the operator $\mathrm{K}_{\mathrm{S}}$, as it 'receives its meaning from the dichotomy of excluded and admitted scenarios' Hintikka, 2007: p. 15). So it is frequently opposed to glut theorists that if rational agents believe by evidence that $\mathrm{p}$, then they are intended to rule out that not $\mathrm{p}$. Conjunctivists can dodge this allegation. They can accept evidentialism in any respect, at the same time admitting that the evidence of contradictions, just as any other sort of evidence, is contrastive. A conjunctive paraconsistent epistemology would thus concede that rational gluts occur conjunctively but not distributively: there can be some ' $B_{s}(p \wedge \neg p)$ ', but there cannot be any ' $\mathrm{B}_{\mathrm{s}} \mathrm{p} \wedge \mathrm{B}_{\mathrm{s}} \neg \mathrm{p}$ '. The intuitive accordance of 'good evidence' with $\mathrm{AE}$ is respected.
} 


\section{Three paradoxes}

To see how the hypothesis may work, let us see three examples of paradoxes that can be legitimately considered (by dialetheists) true contradictions. They will be presented here in the question-and-answer approach suggested for the non-adjunctivist computer of Sect. 1.2, which allows for an epistemic-pragmatic evaluation (concerning what believers or speakers believe or assert). ${ }^{17}$

\subsection{Two errors}

A quite famous Liar-like paradox (see also Sect. 4.2) is the sentence E, which says:

There are two errors in in this sentence.

At first, E seems to be false, because there is only one error in the sentence, but if it is false, then it must be true, because then there are two errors, the repetition of 'in' and the fact that it says there are two errors. However, if there are two errors, then ' $E$ ' is true, and there is only one error. So we get the typical result: if there is only one error (E1) then there are two (E2), and if there are two there is one. As the errors are at least one and no more than two, we have the Inclosure Schema: $E \leftrightarrow \neg E$. In the dialetheist diagnosis, this means, via Excluded Middle, that $E \wedge \neg \mathrm{E}$ is true, and is to be accepted as such (Sect. 1.3).

Suppose now an ideal-typical naïve believer $\mathrm{S}$, who is asked: 'how many errors are there?'. Very plausibly, S begins by answering 'only one' or 'two', and then she possibly discovers the trick concealed in E. Now the dialetheic conclusion may make some sense: $\mathrm{S}$ may concede that the sentence ' $\mathrm{E}$ ' is a strange case of 'two-one' mistaken sentence, which presents only one error and two errors at the same time, and whose description in terms of ' $\mathrm{E}$ and not $\mathrm{E}$ ' has some plausibility (C1). However, if questioned about 'E1?' or 'E2?', S would not accept one or the other option (C2), and she would not be able to go back to her previous view: the possibility of believing (or assuming) separately one or the other is excluded (C3). ${ }^{18}$ The important point is that E1 and E2 are not definitely false for her, because, ultimately, she sees that there is only one error, and there are two errors. They are not false but cannot be said to be true either: as it were, they are two 'gaps', whose joined occurrence makes one glut.

\footnotetext{
17 The erotetic-dialogical approach is typical of the analysis of paradoxes in the philosophical tradition (see Sorensen, 2003a). In fact, it does not imply any substantial difference with respect to the current monological style, at least for what we are concerned here (the possibility of true contradictions of conjunctive form). About the substantial continuity between dialogical and monological approaches in deductive logic see Dultilh Novaes (2021).

18 Such a situation might be modelled in various ways, by logic of revision belief, or by adaptive or dynamic logic. The account here proposed wants to be informal, later the problem will be tackled in more detail (see Sect. 4.2). In passing, it should be noted that, to support the conjunctive interpretation of E, the Author has personal evidence, based on twenty years of teaching logic and paradoxes to students. Since there have been around two hundred students every year, the sample is not so restricted, ultimately.
} 
In this account, the conjunctive approach does not change the basic dialetheist conclusion: paradoxes of this kind release true contradictions. What changes is how the notion of 'true contradiction' is interpreted. While a di-aletheist account of the question-and-answer situation would imply 'yes' and 'yes' for both the questions 'E2?' and 'E1?' (see Priest, $1987^{2}$ : 61; and here Sect. 4.1), for conjunctivists the answers are 'no' and 'no', which are interpretable, if you want, as 'not exactly' and 'not exactly'. The difference is subtle, but the consequences might be interesting.

It should be noted that in this way Conj is able to incorporate the gap-theory intuition (that paradoxes are neither true nor false sentences); but the diagnosis is included in a glutty picture, as $\mathrm{E}$ is held to instantiate a contradictory state of affairs. The conclusion (that ' $\mathrm{E}$ and not $\mathrm{E}$ ' is true) tells us that truth as such does not fail: $\mathrm{S}$ is perfectly able to diagnose the situation, and to describe it in a true (and plausibleacceptable) way. Another noteworthy point is that the 'gaps' mentioned by C2 occur for unassertability (Sect. 4.3). S does not like to accept 'E1' or 'E2' separately, not in virtue of some epistemic under-determinacy (she knows everything about E), or some other hitches (say, category mistakes, failed presuppositions, contingent futures, etc. — see Priest, 2008: pp. 130-133), but because she positively knows that 'E1' and 'E2' are partial (and specifically instable) state descriptions. Evidently, not any partial truth is untrue (or unassertable) but the particular incompleteness of 'E1' and 'E2' as separate assertions makes them visibly misleading: in asserting that there is only one error S conveys the idea that there are not two errors, which is untrue, and will be promptly disproved. ${ }^{19}$ Over-determination so makes the two sentences untrue and unassertable, for the same reason why it makes their conjunction assertable and true.

\subsection{The frog-tadpole}

Another typical dialetheic case is the case of borderline properties. Between frog and tadpole there are infinite stages (Cargile, 1969), so that in the central area of the process we can see there are some points in which there is a frog that is not a frog, and the contradiction becomes (in some dialetheic sense) "visible'. ${ }^{20}$ If $\mathrm{S}$ is asked about a specific frog-tadpole (and she is willing to accept the contradiction), she will admit that there is a contradictory state of affairs, which deserves the description 'this is a frog that is not a frog', so something like ' $F a$ and not $F a$ ' (C1). But now asked about ' $\mathrm{Fa}$ ?' she would not say 'yes', without the other part of the story, and would not even believe that $\mathrm{Fa}$ (C3). She will honestly acknowledge that the object she is speaking about is not 'exactly' a frog, as it lacks having some typical

\footnotetext{
19 Interestingly, in the erotetic - traditional-presentation of the Liar paradox (see Diogenes Laertius, 2, p. 108, ed. J. Miller, 2018: p. 113) the bi-conditional contradiction was specifically intended to convey a 'no-no' answer: face to the question 'is the Liar lying?' the respondent could not say 'yes' on pain of refutation, as the questioner would in turn say 'then you mean no!'; and she cannot say 'no' for the same reason (see on this d'Agostini, 2008).

20 The concern here is not vagueness as such, but the plausibility of the three conjunctivist theses, so I do not consider the difference between the conjunctive approach and other options, in general, and specifically in the dialetheic ('subvaluationist') interpretation (Cobreros, 2013; Priest, 2003).
} 
(essential) properties that frogs have in any possible worlds; and it is not 'exactly' a tadpole either, for the same reason $(\mathrm{C} 2)$.

Here we see the weird point of Conj: a true (assertable and acceptable) state description is made of two untrue (unassertable and unacceptable) sentences. Again, there is no 'failure' of truth, strictly speaking, because there is a state of affairs positively occurring, which is understandable, and describable, as such. What fails is our will to isolate the property $F$ (being a frog) as applied to $a$, from not $F$ (in this case, from 'being a tadpole'). And it is this specific failure by over-determination (see Sect. 4.2) that $\mathrm{C} 2$ intends to stress.

Interestingly, experiments about borderline evaluations have shown that the conjunctive interpretation makes sense. In the case of typically vague predicates, such as 'tall', naïve speakers generally accept that a certain man $b$ is tall-and-not-tall but are unwilling to accept an instance of the Excluded Middle, that either ' $b$ is tall' or ' $b$ is not tall' is true. ${ }^{21}$ This does not simply mean that they want 'a third possibility'. Rather, they are aware that the contradiction is true (is made true by an actually occurring state of affairs), but the two 'epistemic parties' separately defending ' $b$ is tall' and ' $b$ is not tall' are both wrong, simply because they offer an incomplete state description as it were the whole truth.

\subsection{Fortunate misfortune}

A third case is the paradox of the fortunate misfortune (Smilansky, 1994, 2007). A young girl, Abigail, was born with a combination of unfortunate defects concerning her legs and breathing. To correct them she needed to learn to swim and to continue swimming in an intensive way, which she did, so that, after a certain number of years, her breathing and legs became normal. Meanwhile, she became an excellent swimmer, to the point that she won the women's world backstroke championship for many years (Smilansky, 2007: p. 12).

What can we say about Abigail? Was she fortunate, or unfortunate? Both? Neither? She was both, in a sense, but we cannot exactly say that she was one thing or the other. The appropriate description of Abigail's case is that her misfortune has made her fortunate, ${ }^{22}$ and surely, in the end, fortune was dominant, but in our evaluation of the entire case (and similar cases), we cannot honestly say that Abigail has one or the other of the two incompatible properties, taken separately.

Given ' $\lambda$ ' for Abigail, and ' $\Phi x$ ' for ' $x$ is fortunate', we ought to ascribe to $\lambda$ a complex property, which makes her both fortunate and unfortunate, so ' $\Phi \lambda$ and not $\Phi \lambda$ ' will be true (C1). The account in terms of conjunction and negation is justified, 'not' marks the anti-extension of a property (see Sect. 3.1), and the 'and' conjoins two well-formed sentences that we infer from the evidence of a

\footnotetext{
21 Serchuck, Hargreaves and Zach (2011). Mentioned by Cobreros et al. (2015: pp. 379-380), who draw conjunctivist conclusions for contradictions at the borders.

22 As Smilansky rightly notes, Abigail's fortune strictly depends on her misfortune. It is not comparable, for instance, to the case of a person who has an accident, and at the hospital finds the person who will be the passion of her/his life. In this case, the person's fortune is not strictly related to her/his misfortune.
} 
state of affairs (see Sect. 3.2). But we cannot accept that $\lambda$ (Abigail) is only one thing or the other, for the same reasons that we cannot accept ' $F a$ ' ( $a$ is a frog) or 'not $F a$ ', and 'E1' (that there is only one error in E) or 'E2' (C2). Actually, if we accept ' $\Phi \lambda$ ' separately, then we are led to infer for $\lambda$ what we would infer for any ' $\Phi x$ ': for instance, that she does not deserve our compassion and admiration; or, alternatively, if we accept 'not $\Phi \lambda$ ', our compassion would make us forget or underrate what she was able to achieve from her own disadvantage (C3).

One can justify the refusal of separate assertion in this case by appealing to pragmatic as well as metaphysical considerations. From a pragmatic point of view, ' $\lambda$ is fortunate' is unacceptable because it is a partial and misleading state description. In asserting only ' $a$ is [is not] a frog' or ' $\lambda$ is [is not] fortunate', I mislead people who may infer from my assertion untrue consequences. So we can say that the conjunctive account aims at observing the maxim of quantity. Notably, the reason why the maxim should not be violated (in contradictory cases as in many other cases) is that incomplete assertions easily convey falsities. Thus, one would say that Conj also respects the maxim of quality (truthfulness). If we adopt instead a metaphysical view, we ought to concede that the two properties are so strictly connected that any separate account seems to misrepresent the situation (Sect. 3.2). They are 'fused' together, but in a special way. In Kit Fine's truthmaker semantics, there is a variety of ways in which states (facts) can be combined or joined: 'We must allow, for example, that one state may be a part of another, as when the presence of rain is part of the presence of rain and the wind, or that two states may fuse to a single composite state, as when the presence of rain and the presence of wind fuse to the presence of rain and wind view' (Fine, 2017: p. 559). As to 'fusion' as such, for Fine the most natural sense is not properly 'conjunctive': 'there is a natural sense in which facts may be fused. So for example given the fact $f$ that this ball is red and the fact $g$ that it is round, there will be a fused fact f. g' (Fine, 2012: p. 72). This 'natural sense' of fusion admits of simplification: having a red ball, we can truthfully say 'it is red' and separately 'it is round'. But the fusion of redness and roundness does not seem comparable to the joint occurrence of $\Phi$ and not $\Phi$ in $\lambda$ 's case. The two properties mutually interact in a way that is sensibly different from the ordered and disciplined way in which forms interact with colors (Sect. 3.2).

Briefly, what we can see in these three cases is that the properties we ascribe to objects do not always have well-defined borders, sometimes we cannot distinguish the extension and the anti-extension of a given property. And this may hold for any sort of property: for semantic properties (being a sentence with two errors) as well as for natural properties (being a frog), or for value properties (being a fortunate girl). The idea implicit in C2 is namely that contradictions may occur, and we have 'good evidence' of their occurring (Sect. 1.5), but they occur as a failure of our will to believe that $\mathrm{p}$ or to believe that not $\mathrm{p}$; and an honest speaker or believer should acknowledge this failure (C3). In this sense, the conjunctive treatment of paradoxes, implying a combination of two epistemic gaps for one glutty state, seems to introduce a new way of being glut theorists. 


\section{Open problems and possible solutions}

The conjunctivist view seems to be plausible in the framework of an informal and epistemic-pragmatic account of paradoxes, but the benefits of the theory (for instance, the possibility of recapturing AE) might not exceed the logical costs. ${ }^{23}$ As mentioned in the opening, the aim of the article is not to show the 'superiority' of Conj with respect to other positions, but to explore its plausibility as a rational theory of non-explosive true contradictions. The approach is thus mainly 'pre-logical'; it is focused on the reasons we may have in interpreting the possible occurrence of contradictions in the way intended by $\mathrm{C} 1, \mathrm{C} 2$ and $\mathrm{C} 3$. $^{24}$

In the following, I will propose only some ideas for further inquiries, focusing on the three main questions: what is the meaning of 'not' for a conjunctive conception of true contradictions? is the conjunctive 'and' still an 'and'? what is the postulated meaning of 'truth'? Negation and conjunction will be dealt with in this section, truth in the next one.

\subsection{Yes, but not exactly}

Conjunctivists can accept the dialetheic conception of negation in all its basic features. 'Not' is meant to be a contradiction operator (as in classical logic); it has 'partial' and 'positive' content (so is not metaphorically comparable to complementation or cancellation); and it is pragmatically distinct from 'rejection' (accepting 'p and not p' does not mean accepting and rejecting 'p' at the same time). The difference appears as soon as truth is involved.

As Priest states $\left(1987^{2}\right.$ : p. 61), 'it well may be that if a person is asked whether A or not A, she can of course say "yes and no" without meaning that she both accepts and rejects $\mathrm{A}$, rather that she accepts both A and not A'. Conjunctivists can approve of such a picture. What they specify is the not exactly idea suggested in Sect. 2.1: when 'yes' means 'yes, this is true', the speaker or believer has an alethic

\footnotetext{
23 In particular, the admission of di-aletheias allows dialetheists the possibility of preserving the usual meaning of negation and conjunction, and a completely unrestricted application of the T-schema. While, as it seems, Conj requires us to renounce the left-to-right direction of CT, but also some aspects of negation (namely the equivalence with falsity), and the admittance of C2 (the 'two gaps' of a conjunctive contradiction) seems to restrict the import of the schema. A detailed confrontation between glutty dialetheism and conjunctivism (respective costs and benefits) cannot be the concern of the present paper, but as it will be specified in the following, Conj might not be so far from dialetheism in treating these problems. The main difference ultimately rests on the fact that for conjunctivists a true contradiction logically behaves as an atomic sentence (Sect. 3.2). This difference seems to be decisive, as it may imply that conjunctive contradictions are not contradictions, after all.

24 'Pre-logical' are all those extra-logical considerations that ground (so explain and justify) the logical choices. They are basically metaphysical, epistemological, pragmatic considerations; they concern the nature of reality as we know it, the right to believe that what we believe is actually the case, the conversational rules that govern our assertive behaviour. As such, a pre-logical perspective is typically adopted in philosophical logic, especially when one should justify revisions of the classical apparatus. Evidently, a pre-logical view is preparatory (as the suffix 'pre-' implies) which means it does not exclude rather requires the further development of a logical account.
} 
commitment, which implies exclusion. ${ }^{25}$ 'Not exactly' is to some extent equivalent to 'yes, but...', both are ways in which one expresses partial truths, but more specifically, one ought to say 'yes, there are two errors in E, but not exactly two'; 'yes, Abigail is a fortunate girl but not only this'; and 'yes, $a$ is a frog, but not exactly a frog in all respects' (the reference to 'exactness' is especially important, as it may recall the conception of truth that is involved in Conj: Sect. 4). An honest and informed speaker or believer who faces some ' $p$ and not p' would not reject 'p' or 'not p' but would be unwilling to assert or to assume each separately.

The arguments in favor of this view mainly concern the pragmatics of "yes and no' (Ripley, 2011), but the idea may also have some metaphysical groundings. In the conjunctive view, 'not' works classically as a border operator, it marks the extension and the anti-extension of a property (see Sect. 2.2). In most cases, borders are uncontroversially exclusive, and so falsity, with its exclusive import, is equivalent to negation. In some other (rare) cases instead, we have a complex object-fact, endowed with a complex (internally contradictory) property, and we cannot describe it otherwise than by ' $p$ and not p', so we have a dialetheia: ' $p$ and not p' is held true. Now negation is no longer exclusive, but the metaphysical correlate of 'not' is always the same: it still 'names' or 'describes' the border of the property. If conjunctivists are willing to accept this approach, they may find some support in David Armstrong's late treatment of negatives (Armstrong, 2010: p. 79 ss.), whereby 'not' is 'the cutter', as it marks the limits of properties or states of affairs. They would thus say that contradictory states are situations in which negation plays its usual role, but does not have any alethic autonomy: the truthmaker is the 'total fact', joining $\mathrm{p}$ and not p. Such a view is nicely adaptable to Beall's idea mentioned in Sect. 1.5: that in the case of dialetheias, negation is 'on holiday', it forgets its task of excluding the opposite. Because in this sense, the determining role of negation is preserved (as border operator), but the exclusionary role of truth is preserved too.

\subsection{And?}

In proposing the failure of Simplification, Conj encounters at first the objection already seen for Non-Adjunctivism: is the 'and' still an 'and'? Non-adjunctivists can support their view by appealing to plausible cases in which non-adjunctive 'ands' are used without betraying the ordinary meaning of the operator. Conjunctivists should adopt a similar strategy, and one may suppose the research is not so difficult, as in natural language there are many cases of unreducible 'and' that 'cannot be

\footnotetext{
25 See Priest, 2006: 'this raises the question of when the uttering of a negated sentence is to be interpreted as an assertion and when as a denial. There is, in general, no near answer to this question' (p. 105). Much depends on the connections between assertion and acceptance, denial and rejection, one is willing to postulate (see Murzi \& Carrara, 2015). Priest (2006: pp. 103-115) develops a complex account of the interrelation between the two dualities. Here I suppose Conj can endorse a simpler view, by assuming that cognitive states (beliefs) and speech acts (assertions), not unlike inferential premises (assumptions), formally require some alethic commitment (see Sect. 4.3).
} 
anything else than an "and". ${ }^{26}$ A classic case of divorce between distributive and collective predication (Oliver \& Smiley, 2013: pp. 25-28) is mentioned in Plato's Hippias Major. Hippias asserts that 'whatever is true of two together is also true of each' (302b); Socrates counters that if so, then 'if two is what we together are, then two is what each of us must be as well' (301e), which is absurd. Traditionally, it is a simple fallacy of division. But Socrates's example involves the case of numerical predicates, which do not express simple empirical properties such as 'being red' or 'being round' (Sect. 2.3), but special (second order) properties. Now we can note that 'true' is a predicate-property of this kind. So there are reasons to postulate that the same holds for T: if you and I are two, this does not mean I am two and so are you, and similarly, that a collection of truthbearers is true does not necessarily mean its members are (to be equally said) true as well.

The thesis seems odd, prima facie, but reasonable accounts of truth can support it. In a semantics of exact truthmaking the CT mentioned at the beginning of this paper does not hold unrestrictedly, and it may fail namely in the left-to-right (only if) direction: an 'exactly' true conjunction does not necessarily entail the exact truth of its conjuncts. The example mentioned by Rodriguez-Pereyra (2006) is simple. A proposition is true in virtue of the state of affairs or fact that makes it true. Suppose 'Peter is a man and Saturn is a planet', which is true: it is made true by the fact that Peter is a man and Saturn is a planet. But 'it is not the case that 〈Peter is a man〉 is true in virtue of the fact that Peter is a man and Saturn is a planet; it is simply true in virtue of the fact that Peter is a man' (Rodriguez-Pereyra, 2006: p. 970). The Conjunctive Thesis, whereby ' $e$ is a truthmaker for $\langle\mathrm{P} \& \mathrm{Q}\rangle$ if and only if $e$ is a truthmaker for $\langle\mathrm{P}\rangle$ and $e$ is a truthmaker for $\langle\mathrm{Q}\rangle$, does not hold'. ${ }^{27}$ This confirms that 'and', when seen from a metaphysical point of view, does not always satisfy Simplification. Clearly, in the example mentioned by Rodriguez-Pereyra the entailment fails because there is no semantic or metaphysical 'proximity' between the conjuncts, while what is postulated by Conj is the opposite: Simplification fails because the conjuncts are strictly connected; so strictly, that they cannot be separated. What, then, is the structure of the contradictory truthmaker postulated by Conj?

A reasonable objection addressed to conjunctivists (see Sect. 1.5) is that in virtue of the Fundamental Condition, the joined incompatibles must be two distinct terms (propositions, beliefs, states of affairs), while their 'fusional' view seems to imply that there is in fact only one term. The problem of 'two or one fact?' for the metaphysics of contradiction has been raised by Armstrong (2004: pp. 107-108). If we decide to accept that a contradiction is true, should we postulate one fact ('the very same entity or collection of entities'), simultaneously working as a truthmaker and falsemaker of 'p'? Are there instead two distinct facts, $\mathrm{p}$ and $\neg \mathrm{p}$, both acting as truthmakers for ' $p \wedge \neg p$ ', and each simultaneously as falsemaker for the other

\footnotetext{
26 See Schein (2017: pp. 97-99) for many examples. As Schein stresses, the idea that any unreducible 'and' is not really an 'and' is an 'Aristotelian fallacy' that should be revised (p. 97).

27 The idea was originally presented in the context of a discussion about the Entailment Principle (Rodriguez-Pereyra, 2006, 2009), later developed by different authors, and finally assumed as a distinctive feature of an exact truthmaker semantics (see Fine \& Jago, 2017; Jago, 2018).
} 
conjunct? If we adopt the latter option, 'should it be said that the two sets of truthmakers are identical, or merely overlap, or are disjoint?'. ${ }^{28}$ Dialetheists generally prefer the two-fact account, and if they are truthmaker maximalist (thus thinking that every truth must have a truthmaker), they assume that there are specifically negative facts or states of affairs. In fact, the subsistence of negative facts is controversial in truthmaker semantics, some believe that truthmaker maximalism is unconceivable namely because there cannot be negative truthmakers (see Tallant, 2018). ${ }^{29}$ Conjunctivists would favor the one-fact option, but without overlapping of truth and falsity. They say that a contradictory state (of affairs) consists of only one (positive) state, made of two contradictory parts, and acting as a simple truthmaker for the conjunctive state description. The solution seems quite intuitive. Let us reconsider the three cases suggested in Sect. 2. We have three single states, concerning three single objects: the sentence $\mathrm{E}$ whose odd property is to be a 'two-one' mistaken sentence; the frog-tadpole object whose particular status makes the sentence ' $\mathrm{Fa} \wedge$ $\neg F a$ ' true; and Abigail, who is a fortunate unfortunate girl in virtue of some particular adventures and misadventures that have occurred in her life. So, the two propositions ' $E$ ' and ' $\neg E$ ' are intended to describe two 'parts' of the single object $E$, just like ' $F a$ ' and ' $\neg F a$ ' describe two parts of the frog-tadpole, and the double evaluation of Abigail's case is ascribed to a collection of occurrences concerning the fact-event of her life. In all these cases, the 'and' clause is in order, because there are two properties instantiated in one object, and 'not' plays its natural role of describing the limit of a property, but the entailment by T-distribution fails.

In practice, the adoption of Conj postulates that what is glutty (excessive) is the contradictory case, as it involves the joint occurrence of opposite properties (in stratified, combined or otherwise joined form), but there is no glut for truth: truth and falsity do not overlap. Clearly, this must involve a particular conception of truth.

\section{The underlying conception of truth: preliminaries}

The basic motivation for conjunctivism, in the version here proposed (see especially Sect. 1.5), is the need of an honest admittance of contradictory facts (and pieces of evidence), while maintaining-discussively, expressively and epistemically-the conditions of AE, intended as a grounding rule of reason (and thus of logic). Different approaches to inconsistency may satisfy these (or similar) needs. What is typically shared by dialetheism and conjunctivism, as suggested (Sect. 1.4), is the idea

\footnotetext{
28 Armstrong (2004: pp. 107-108). He also adds: 'it is interesting to consider what paraconsistentists such as Graham Priest should say if they wanted to embrace truthmaker theory also' (p. 108). Priest has never answered, but in personal communication he has confirmed that he tends to keep to the two-state account.

29 There are resources for sorting out the difficulty, for instance Jago (2018) distinguishes negative facts from absences, providing a solution that is not so far from what has been proposed here for 'not' (the border or limit of a state or property). Jago does not postulates glutty truthmakers, but his solution seems adaptable to the hypothesis, once incorporated within a conjunctive (one fact) account (for details, see d'Agostini, 2019a: pp. 154-158).
} 
that a rational use of the notion of truth does not prevent, but rather implies, the acceptance of 'true contradictions' in the conjunctive form. What Conj adds to this picture is that the putatively 'contradictory truth' can be perfectly respectful of AE. So the decisive point is how the predicate-property $\mathrm{T}$ is to be conceived, and how such a conception can be justified.

In Priest's version (see Priest, 2006: pp. 43-55), dialetheism is in principle compatible with any theory of truth. Correspondence, pragmatic, and coherence theories (the classically 'robust' theories), as well as minimalism, redundancy, and deflationism in general, may contemplate the occurrence of dialetheias. 'In talking of true contradictions no particular notion of truth is presupposed. Interpreters of the term "dialetheism" may interpret the notion of truth concerned in their own preferred fashion' (Priest, 2007: p. 131). A deflationary truth theory is proposed by Beall (2009); his 'transparent truth' implies that the 'only T' or 'just T' value, satisfying AE, holds for any non-paradoxical sentence (see Beall, 2009: p. 48). In Cobreros et al. (2012), a similar dualism is interpreted within a semantic-pragmatic approach to borderline contradictions, which is not far from what has been advanced informally here (Sect. 2). The authors assume that ' $\mathrm{T}$ ' is to be used in a strict or tolerant way, and the evaluation of contradictory state descriptions involves tolerant truth.

In the view presented here, one would rather speak of intolerant truth, as the use and meaning of the truth predicate is ruled by the unrestricted exclusion of falsity. There is only one meaning-use of ' $T$ ', and it is 'just $T$ ', satisfying AE; what-for some reason-is not ' just $\mathrm{T}$ ' cannot deserve truth ascription. The conjunctive T-theory is not explosive (as the ECQ does not hold: Sect. 1.5), but it is perfectly 'classical' in this respect: it can be labelled as a 'classical glut theory', following Scharp's taxonomy (2013: p. 23). ${ }^{30}$

\subsection{Truth in disagreement}

For Conj (as it is here intended) contradictory propositions are state descriptions (C1), and they are said true insofar as describing an effectively occurring fact or state of affairs of a contradictory nature (so being made true by special, glutty facts: Sect. 3.2). The meaning of the truth predicate is thus not far from what was intended by Plato or Aristotle: a proposition is (can be said) T iff it 'says how things stand' (Plato, Cratilus, 385c: ta onta legei os estin). ${ }^{31}$ The commitment to the ta onta principle (as traditionally intended) postulates that the action of 'saying' in assertive cases (when truth is formally required) is ruled by actuality (true 'in the actual

\footnotetext{
${ }^{30}$ Evidently, the 'glut' does not regard truth (as there is no overlapping of truth and falsity), but the somewhat 'excessive' nature of the contradictory truthmaker (see Sect. 3.2).

31 William Alston's 'alethic realism' provides a similar version of the traditional definition (see Alston, 1996). This kind of T-realism does not strictly imply some isomorphism or correspondence or one-to-one relation between reality and language. Furthermore, it is not incompatible with some form of logical or ontological deflationism (see Alston, 1996: pp. 26-32), while being perfectly consistent with a truthmaker conception, which 'does not commit to any kind of substance realism' (Rodriguez-Pereyra, 2005: p. 21).
} 
world') ${ }^{32}$ and completeness ('the whole truth'). It is assumed, in practice, that in saying/believing that ' $\mathrm{p}$ ' is true the speaker or believer implies that she accepts/ believes that $\mathrm{p}$, and everyone should accept/believe it, because 'things stand in that way'. All of this is only formally, or ritually, required, which means $\mathrm{S}$ might lie (she asserts 'p' but does not believe-accept that $p$ ) and/or might be wrong (things do not stand in that way), but this is the special commitment conveyed by the use of the predicate.

Tested against this notion of truth, Non-Adj and di-aletheism reveal some explanatory and interpretative limits, while Conj seems preferable. Paradigmatic nonadjunctive cases belong to three situations: the impersonal system (Varzi's computer), possible worlds semantics (Rescher \& Brandom, 1980), and the discussive scenario postulated by Jaśkowski or other authors. In the first case, the system perfectly satisfies completeness, but it is not entitled to evaluate the contents involved ('the things'); one would say the system is analetheic, or T-free. In the second case, we speak of 'true-in-two-worlds', and so the actuality restriction does not hold. In the third case, there are different options, but the most easily adaptable to concrete non-adjunctive cases is the interpretation of the situation as involving perspectival truth, or $\mathrm{T}$ 'according to the story told by an epistemic agent'. When we face a discussive situation in which $\mathrm{X}$ says that $\mathrm{p}$ and $\mathrm{Y}$ says that not $\mathrm{p}$, non-adjunctivists as well as di-aletheists postulate they might both be right. However, if by 'being right' we mean that they tell the truth (in the intended sense), then Non-Adj is out of the question, as it regards truths in different worlds or stories. Dialetheism seems preferable, as we can speak of ' $\mathrm{T}$ ' in the traditional sense: there is a contradictory state that makes ' $\mathrm{p}$ and not $\mathrm{p}$ ' true, and $\mathrm{X}$ and $\mathrm{Y}$ are discussing about it. But if it is so, then we can see that 'p' and 'not p' are partial accounts of facts, and we cannot say that $\mathrm{X}$ and $\mathrm{Y}$ are 'both right' (as di-aletheists would postulate). Rather, they are both wrong, as they would present their partial view as the whole truth. Actuality is respected; completeness is violated. So, if ' $T$ ' is meant to be the complete-actual truth, then there is no possible-conjunctive or distributed-di-aletheic case. ${ }^{33}$

In contrast, Conj seems more adaptable to the ancient (exact, intolerant) truth theory. The conjunctive view simply adds to the dialetheic treatment the idea that if you take 'this is T' as ruled by completeness and actuality, then neither X's nor Y's position is tenable. They cannot both be right, as long as they intend to present their thesis as the whole truth in our world, because this is simply untrue. ' $\mathrm{Fa}$ ' or ' $\mathrm{E} 1$ ' or ' $\Phi \lambda$ ', as well as their negative counterparts, separately taken, do violate the ta onta principle in both requirements of completeness and actuality: things in our world do not stand exactly in that way.

\footnotetext{
32 That $\mathrm{p}$ is true 'for' the actual world does not exclude that ' $\mathrm{p}$ ' could be about possibilities and necessity, so events and states of other worlds (about misunderstandings coming from truth in a world-for a world d'Agostini, 2019b).

33 The limits of theoretical positions that allow for compatibility in the case of doxastic disagreements are well enlightened by Marques (2014: 123). A similar discussion applied to the dialetheic theory of disagreement can be found in Murzi and Carrara (2015).
} 


\subsection{The Liar's challenge}

For conjunctivists truth is indefectibly marked by AE, and LND2 holds unrestrictedly. In this respect, they ought to face an important challenge: the Liar paradox seems to provide a strong justification for di-aletheism and a clear counter-example to LND2 and AE. ${ }^{34}$ At first, the epistemic-pragmatic account proposed for the three paradoxes (Sect. 2) can be applied to the Liar. Given ' $\mu$ ' (the sentence which says of itself it is false or untrue), an ideal agent questioned about ' $\mu$ ' would not answer 'yes' to ' $\mu$ ?' or 'not $\mu$ ?' without adding any further specifications (C3), as she knows that if ' $\mu$ ' is true then it must be untrue, and if it is untrue, it must be true, so both ' $\mu$ ' and 'not $\mu$ ' as such are for her unassertable and untrue (C2). However, this does not necessarily mean that the Liar's assertion is (for her) a truth-value gap. She can acknowledge, along with dialetheists, that the sentence instantiates a weird and selfcontradictory state, whose description ' $\mu$ and not $\mu$ ' is simply (only) true: it is an adequate state description, made true by some (semantic) state of affairs $(\mathrm{C} 1)$.

To make the account a bit more technical, one may begin by postulating that ' $\mu$ ' is to be considered as an assertion. Normally, assertion-sensitive treatments of the Liar (Goldstein, 2000, 2006; Jago, 2018, Ch. 10) are intended to show that there is no (true) contradiction. It is claimed that the sentence ' $\mu$ ' fails its assertive aim, namely in virtue of $\mathrm{AE}$. 'The function of an assertion $\neg \mathrm{A}$ is to reject $\mathrm{A}$ ', so 'the dialetheist who asserts a contradiction $\mathrm{A}, \neg \mathrm{A}$ will be both accepting and rejecting the content of A, and this is surely rationally impermissible' (Jago, 2018: p. 288). In fact, as we have seen (Sect. 3.1) negation for both dialetheists and conjunctivists is not rejection, rather, for conjunctivists it has no 'excluding' property as such, if it is not accompanied by truth. Conjunctivists can perfectly accept that asserting ' $p$ ' means excluding 'not p', but this is because asserting that $p$ means to imply that ' $p$ ' is (believed/assumed as) true, with consequent commitment to AE. As seen, this does not prevent them from acknowledging that ' $\mu$ and not $\mu$ ' is true and can be asserted as such.

To see how this may work, let's see a version of the Liar argument that is not far from what is normally proposed by dialetheists (see Priest, 2006: pp. 107-108), but makes the hypothesis more clearly visible (especially for its affinity with the cases mentioned in Sect. 2). If assertions are truth-implying, ${ }^{35}$ then what the Liar conveys in an assertive context is that it is true that what she is saying is untrue (or false). The form of ' $\mu$ ' which deserves alethic analysis (and therefore can be said true, or false, or neither or both) is thus:

(*) $\mathrm{T}\langle\neg \mathrm{T} \mu\rangle$.

Now the argument that draws the contradiction may run in this way:

\footnotetext{
${ }^{34}$ Thanks to an anonymous referee for pressing me on this point.

35 There are controversies about the T-implication or B-implication of assertives (see Marsili, 2018: pp. 638-648), suffice it to say that the evaluation of assertions implies believed truth as formal requirement (which does not exclude the speaker might lie or be wrong), which is in the line with the right to left side of the T-schema (capture).
} 


$\begin{array}{lll}\mathrm{C} 4 & & \\ 1 & \mathrm{~T}\langle\neg \mathrm{T}\langle\mu\rangle\rangle & \\ 2 & \mathrm{~T}\langle\mu\rangle & \text { Df. } \mu 1 \\ 3 & \mu & \text { T-Out 2 (Rel.) } \\ 4 & \neg \mathrm{T}\langle\mu\rangle & \text { T-Out } 1 \\ 5 & \neg \mu & \text { T-Out } 4 \\ 6 & \mu \wedge \neg \mu & \wedge I 3,5\end{array}$

Notably, to get $\mu \wedge \neg \mu$ there is no need for the Excluded Middle, nor does one need to discharge the hypothesis, as (*) is given by the Liar herself, in her same asserting ' $\mu$ '. Note also that such an account of the Liar corresponds to a quite traditional way of working with the paradox. It is in line with the old idea, widely shared in traditional researches about paradoxes, that Liar-like contradictions involve complex predicates or concepts, related to properties whose stratification (material iteration, diagonalization, indefinite extensibility, etc.) may produce (or seems to produce) the joined occurrence of what in principle cannot jointly occur. ${ }^{36}$ But what is relevant for the conjunctive hypothesis is that here ' $\mu$ ' results an object endowed with a complex, internally contradictory, property-predicate, in line with what has been proposed in Sect. 2 for E, $a$, and $\lambda$ : they all are weird objects, instantiating contradictory properties.

However, the properties of ubiquity (capture) and factivity (release) typical of truth (if the T-schema holds unrestrictedly) have consequences that conjunctivists may judge problematic. The same occurrence of the paradox apparently legitimates T-distribution, in some di-aletheic form, as it conveys both D1 and D2, and the former in virtue of the latter. In $\mathrm{C} 4$, we get $\mu \wedge \neg \mu$, and then we assume the dialetheic non-di-aletheic conclusion $\mathrm{T}\langle\mu \wedge \neg \mu\rangle$, but to arrive at this from $\left(^{*}\right)$, we first get $\mathrm{T}\langle\mu\rangle$ $(D f . \mu)$, then $\neg \mathrm{T}\langle\mu\rangle(T-O u t)$, so we can also conclude with the obvious intuition that ' $\mu$ ', ultimately, is true and untrue, as $\mathrm{T}\langle\mu\rangle$ and $\neg \mathrm{T}\langle\mu\rangle$ both hold, so D2 is confirmed.

To avoid this difficulty, conjunctivists essentially have two options. They can claim that the property-predicate which the Liar's sentence ascribes to itself is not 'truth', actually; or at least it is not that sort of truth we use in epistemology, and in the pragmatics of language, as a feature of beliefs and assertions. Thus, conjunctivists would be committed to distinguish 'logical truth' (transparent truth) from other alethic devices (a hypothesis that is to be found in Beall, 2019), so stating that the conjunctive treatment only holds for extra-logical conceptions of truth. Perhaps this is not a good solution, particularly if conjunctivists want to keep to the idea that there must be only one 'truth', the above seen actual and complete (exact and intolerant: Sect. 4.3) truth, which must hold for any T-ascription, and for logic as well as for any other sector or area of concern. Another strategy is to assume a relevance semantics, whereby the conjunction of step 6 in $\mathrm{C} 4$ is a 'fusion'. This means that 'and' works as a premise binder, so that 2 and 4 are 'inseparable': once you obtain

\footnotetext{
${ }^{36}$ For developments of Tarski's aetiology of the Liar (Tarski, 1944) along the lines of conceptual iteration and instability, see Gupta (1982), Gupta and Belnap (1993), Dummett (1993), Simmons (1993), Cook (2007), Field (2007 and 2008: pp. 25-28, 34-36), Scharp (2013: p. 35 and ss).
} 
' $\mathrm{p}$ and not p' in a relevant proof you cannot go back to 'p' or 'not p'. In this sense, the conjunction is to be held an intensional-content-sensitive-operator. ${ }^{37}$ In line with this solution, one would say that the true sentence, in the Liar's case, is not ' $\mu$ ', but ' $\mu$ and not $\mu$ ', so it is rather admitted a distinction between $\mu$ (in Italic) as the fact of the Liar's assertion (which is the special glutty fact we have seen, similar to the other contradictory facts mentioned in Sect. 2) and ' $\mu$ ' as the sentence uttered by the Liar. This would be in accordance with what has been suggested in Sect. 3.2: the truthmaker is one (Sect. 3.2), the best description we can give of it is ' $\mu$ and not $\mu$ ' (which would justify the di-aletheists' counter-objection, seen at the end of Sect. 1.5).

\subsection{Exact and intolerant truth}

The aim of this article is to explore the plausibility of Conj as a rational theory of non-explosive true contradictions, giving a preliminary (and mainly pre-logical) account of the hypothesis. A semantics for conjunctivism, and a formal development of the consequent truth theory, will be dealt with in other papers, but some ideas for future work can be anticipated. ${ }^{38}$ To keep to what has been here suggested, a consequent logic for Conj ought to be a natural deduction whereby assumptions (premises) belong to the class of assertives, and so have 'a word-to-world direction of fit'. Propositions - as required by $\mathrm{C} 1$ - are state descriptions, they intend to capture an occurring or occurred fact or state of affairs, and this holds for any proposition, contradictions included. The T-schema would work, quite traditionally, as an intersubstitutivity rule so that, in an inference, if you have ' $p$ ' you are in the condition of inferring that $\mathrm{T}\langle\mathrm{p}\rangle$ and if you have $\mathrm{T}\langle\mathrm{p}\rangle$ you infer ' $\mathrm{p}$ ', and you will have Release or T-Out: $\mathrm{T}\langle\mathrm{p}\rangle \rightarrow \mathrm{p}$, and Capture, or T-In: $\mathrm{p} \rightarrow \mathrm{T}\langle\mathrm{p}\rangle$, simply because $\mathrm{T}$ ascriptions require that the truthmaker subsists, and if the truthmaker subsists, the state description is $\mathrm{T}^{39}$

\footnotetext{
37 Priest (2015) presents an idea of "fusion" which is different from both Mares (2012) and Fine (2012). The conjunctive 'and' seems to be closer to what Mares postulates, especially because it is included in a situation-sensitive semantics.

${ }^{38}$ In the current literature there are different proposals (in relevance logic, in adaptive or dynamic logic, in hyper-intensional logic), that can be profitably applied to a conjunctive (or fusional) approach to contradictory conjunctions.As mentioned, the first proposal of a conjunctive model for contradiction has been given by Beall and Ficara (2014), with specific reference to Hegel's notion of Vereinigung, but with a view on the present feasibility of the project. In principle, some interpretation of FDE could meet the requirement, as it will be suggested here; Cobreros et al. (2015) pragmatic-epistemic semantics moves along a similar direction. Given the nice adaptability of Conj to a 'realistic' theory of truth, a promising approach could be the semantics for exact truthmaker launched by Fine and Jago (2017; see also Jago, 2018: pp. 17-22, and Jago, 2020). In what follows only some tentative and general points will be presented: they are conceived in the framework of an interpretation of FDE but can be-at least partiallysatisfied by other views.

39 Scharp (2013) distinguishes the conditional and the inferential ways of presenting the schema; he uses 'T-In' and 'T-Out' to label the former, 'ascending T' and 'descending T' the latter. The approach of the present paper is classical (at least in this respect), so there is no need to make such a distinction. Capture and Release (Beall, 2007a, 2009) are favoured here, since they are taken to explain the both syntactic and semantic role of the schema as an assertion-assumption rule.
} 
By accepting the schema, one is normally committed to exclude exhaustion, i.e. the possibility of untrue but not false statements, so there would not be gaps (rather, any gap is a glut $)^{40}$ - if anything, the largely realistic commitment to the ta onta (actuality-completeness) implies that if it is not true that a state of affair subsists, then it is true that it does not subsist. In fact, this does not represent a real difficulty, for the endorsement of $\mathrm{C} 2$ (that the conjuncts of a true contradiction are untrue), as the two postulated 'gaps' are not failures of $\mathrm{T}$ as such, but of the assertability rules governing truth (see Sect. 2). These rules imply the mentioned intolerance of the theory, expressed by the postulate that propositions are assertable (and so can be assumed) only if they are just true (strictly true, or true simpliciter). Now, to be 'just true' (jT) means (i) to satisfy the epistemic and pragmatic conditions of assertability (such as being grounded on evidence or other rational sources of justification, and expressing the complete information in the case given and for the Gricean needs); and (ii) to satisfy AE, so that if 'p' is T then ' $\neg$ ' must be untrue, so we have AE1: Tp $\rightarrow \neg \mathrm{T} \neg \mathrm{p}$, which contraposes, and hence: AE2: $\mathrm{T} \neg \mathrm{p} \rightarrow \neg \mathrm{Tp} .{ }^{41}$ Notably, the intolerant truth involved in (i) and (ii) is a ritual (formal) feature of assertions. An asserter, evidently, may lie or may present categorically what she does not know for sure, and falsities or untruths can be hypothetically assumed/asserted, but in the special inferential context in which they are asserted/assumed, they must work as they were strictly true. So logical intolerance requires, as formal requisites, categoricalness, and formal commitment to $\mathrm{AE}$, in the case given and for all the inferential needs. ${ }^{42}$ This is what informs C3: it is postulated an intolerant speaker/ reasoner, whose assumptions must express exclusive beliefs, well-grounded on perfectly exhaustive (complete) evidence, which evidently is not satisfied by ' $p$ ' and 'not p' separately, in case $\langle p$ and not $p\rangle$ is true.

Accordingly, a proposition is unassertable (so cannot be assumed) either because it does not satisfy (i), i.e. the usual features of truth-ascription (it is false, or misleading, or not justified in the admitted ways), or because it does not satisfy (ii): it is a partial description of a contradictory state of affairs. Consequently, there are two different sorts of gaps: gaps for under-determination ('p' does not satisfy (i)) and gaps

\begin{tabular}{llllll}
\hline 40 & The arguments are: & & & \\
\hline 1 & $\neg \mathrm{Tp}$ & $\mathrm{A}$ & 1 & $\neg \mathrm{T}\urcorner \mathrm{p}$ & A. \\
2 & $\neg \mathrm{p}$ & $\mathrm{TR}$ (release) 1 & 2 & $\neg\urcorner \mathrm{p}$ & $\mathrm{TR}$ (release) 1 \\
3 & $\mathrm{~T} \neg \mathrm{p}$ & $\mathrm{TR}$ (capture) 2 & 3 & $\mathrm{p}$ & $\mathrm{DN} 2$ \\
& & 4 & $\mathrm{Tp}$ & $\mathrm{TR}$ (capture) 3
\end{tabular}

\footnotetext{
${ }^{41}$ These formulas express de dicto necessity, they exhibit a meaning of ' $\mathrm{T}$ ' whereby, in any linguistically accessible world (i.e. populated by people whose language we understand), a speaker who asserts/ assumes that $\mathrm{p}$ is true is intended to exclude that not $\mathrm{p}$ is true

${ }^{42}$ Note that in this account, the usual Gricean maxims, with their possible improvements and specifications, are ascribed to the semantic behavior of ' $\mathrm{T}$ '. About the unassertability or uncertain acceptability of partial truths, there is a wide literature, generally related to the misleading nature of incomplete statements (see Saul, 2012). Stephen Yablo has specifically dealt with the problem in case of inconsistencies (Yablo, 2014: pp. 10-14). He interestingly mentions Melanie Klein's theory of newborns that 'must take it on board [...] that the good breast, which turns up when they're hungry, and the bad breast, which is withheld, are the very same breast' (p. 10).
} 
for over-determination ( $\mathrm{S}$ has contradictory evidence, so ' $\mathrm{p}$ ' does not satisfy (ii)). ${ }^{43}$ Gaps for under-determination are submitted to the natural graduality of epistemic considerations, so that the truth values range from $0(\mathrm{jF})$ to $1(\mathrm{jT})$, and propositions are untrue if their value does not satisfy a given (contextually determined) epistemic standard, say: $|\mathrm{p}|=1$ iff $\mathrm{P}(\mathrm{ple}) \geq 0.8$. Thus, the value of gappy sentences of the first kind (under-determined truths) ranges from 0.2 to less than 0.8 ; they are neither $\mathrm{T}$ nor $\mathrm{F}$, and thus cannot be asserted. (One can also assume a dynamic-adaptive view, to the effect that such sentences become assertable when their T-value increases up to 0.8 or more.) Gappy propositions of the second kind (partial statements about over-determined cases), can never be asserted/assumed as such, but the conjunction with their negation is assertable, as it is simply true.

These conditions can be satisfied in a variety of ways (see note 38). Indicatively, while in the two logics favored by dialetheists, LP and FDE, a contradictory proposition 'p' has the value 'both' (true-and-false), and in Cobreros et al. (2012) it deserves tolerant truth, so it is $1 / 2$ or 0.5 true, in the hypothesis here advanced, ' $p$ ' as such is untrue, and unassertable, because it is an incomplete state description and fails to meet AE. Propositions describing the half of a glutty state are special cases of unassertable partial truth. The consequence for Conj-evaluations is that there is no 'both', but the value 'neither' splits into indeterminacy $\left(\mathrm{n}^{-}\right)$and over-determinacy $\left(\mathrm{n}^{+}\right)$. Thus, there are four possible evaluations: $|\mathrm{p}|=1$ iff $\langle\mathrm{p}\rangle$ is $j T ;|\mathrm{p}|=0$ iff $\langle\neg \mathrm{p}\rangle$ is $j T$; $|\mathrm{p}|=\mathrm{n}^{-}$iff $\langle\mathrm{p}\rangle$ is untrue by under-determination; and $|\mathrm{p}|=\mathrm{n}^{+}$iff $|\mathrm{p} \wedge \neg \mathrm{p}|=1$. The two gappy interpretations, respectively, correspond to gaps for ignored (or unproved) truths, and gaps for partial contradictory truths. While $\mathrm{n}^{+}$sentences are unassertable because they do not satisfy AE, $\mathrm{n}^{-}$sentences are unassertable because their truthvalue is not enough, so that (for the given standard) their value ranges from 0.2 to less than 0.8. Interpreting the contradictory value not in terms of 'both' but in terms of a special sort of 'neither', the truth tables change with respect to FDE (see Priest, 2008: pp. 142-162). It is equally assumed that conjunction has the lowest value, and disjunction the greatest: $|\mathrm{p} \wedge \mathrm{q}|=\min \{|\mathrm{p}|,|\mathrm{q}|\} ;|\mathrm{p} \vee \mathrm{q}|=\max \{|\mathrm{pl}|,|\mathrm{q}|\}$. But values are linearly ordered in this way: $1>n^{+}>n^{-}>0$, so that $\left|n^{-} \wedge n^{+}\right|=n^{-}$and $\left|n^{-} \vee n^{+}\right|=n^{+}$. Evidently, $\left|\mathrm{n}^{+} \wedge \mathrm{n}^{+}\right|=\mathrm{n}^{+}$, but for the special case ' $\mathrm{p} \wedge \neg \mathrm{p}$ ', which is 1 , if ' $\mathrm{p}$ ' is a genuine part of a glutty state. ${ }^{44}$ Validity is normally conceived as truth preservation,

\begin{tabular}{|c|c|c|c|c|c|c|c|c|c|}
\hline \multicolumn{10}{|c|}{$\begin{array}{l}43 \text { The question } \\
\text { ply because the } \\
\text { for failed presup } \\
\text { futures and norm } \\
\text { false in possible } \\
\text { mined. } \\
{ }_{44} \text { Truth-tables: }\end{array}$} \\
\hline$\wedge$ & 1 & $\mathrm{n}^{+}$ & $\mathrm{n}^{-}$ & 0 & $\vee$ & 1 & $\mathrm{n}^{+}$ & $\mathrm{n}^{-}$ & 0 \\
\hline 1 & 1 & $\mathrm{n}^{+}$ & $\mathrm{n}^{-}$ & 0 & 1 & 1 & 1 & 1 & 1 \\
\hline $\mathrm{n}^{+}$ & $\mathrm{n}^{+}$ & $\mathrm{n}^{+}$ & $\mathrm{n}^{-}$ & 0 & $\mathrm{n}^{+}$ & 1 & $n^{+}$ & $\mathrm{n}^{+}$ & $\mathrm{n}^{+}$ \\
\hline $\mathrm{n}^{-}$ & $\mathrm{n}^{-}$ & $\mathrm{n}^{-}$ & $\mathrm{n}^{-}$ & 0 & $\mathrm{n}^{-}$ & 1 & $\mathrm{n}^{+}$ & $\mathrm{n}^{-}$ & $\mathrm{n}^{-}$ \\
\hline 0 & 0 & 0 & 0 & 0 & 0 & 1 & $\mathrm{n}^{+}$ & $\mathrm{n}^{-}$ & 0 \\
\hline
\end{tabular}


and the usual rules of natural deduction are preserved. The consequence relation is not 'explosive', as ' $\mathrm{p} \wedge \neg \mathrm{p}$ ' is not simplifiable, so $\mathrm{p} \wedge \neg \mathrm{p}$ does not prove $\mathrm{q} .{ }^{45}$ In practice, a 'conjunctivist' system for natural deduction might be a version of FDE (which contemplates 1, 0, both, neither), though having a special sort of 'neither' instead of 'both'. 46

Funding Open access funding provided by Università degli Studi di Milano within the CRUI-CARE Agreement.

Open Access This article is licensed under a Creative Commons Attribution 4.0 International License, which permits use, sharing, adaptation, distribution and reproduction in any medium or format, as long as you give appropriate credit to the original author(s) and the source, provide a link to the Creative Commons licence, and indicate if changes were made. The images or other third party material in this article are included in the article's Creative Commons licence, unless indicated otherwise in a credit line to the material. If material is not included in the article's Creative Commons licence and your intended use is not permitted by statutory regulation or exceeds the permitted use, you will need to obtain permission directly from the copyright holder. To view a copy of this licence, visit http://creativecommons.org/licen ses/by/4.0/.

\section{References}

Alston, W. (1996). A realistic conception of truth. Cornell University Press.

Armstrong, D. M. (2004). Truth and truthmakers. Cambridge University Press.

Armstrong, D. M. (2010). Sketch for a systematic metaphysics. Oxford University Press.

Barrio, E. A., \& Da Re, B. (2018). Paraconsistency and its Philosophical Interpretations. Australasian Journal of Logic, 15(2), 151-170.

Beall, J. C. (Ed.). (2003). Liars and heaps. Oxford University Press.

Beall, J. C. (2006b). True, false and paranormal. Analysis, 66, 102-114.

\section{Footnote 44 (continued)}

The interesting difference is that in FDE the values that are to be selected, in case of $\mathrm{lb}$ and $\mathrm{nl}$ and $\mathrm{lb}$ or $\mathrm{nl}$, are: $1,0, \mathrm{n}$, so that $\mathrm{lb}$ and $\mathrm{nl}=0$ and $\mathrm{lb}$ or $\mathrm{nl}=1$.

45 That $\mathrm{p}$, not $\mathrm{p}$ does not prove $\mathrm{q}$ either, might be discussed. In this respect Conj is not perfectly dual to Non-Adjunctivism. What is dual, is rather the interpretation of the occurrence of contradictions. As 'p and not p' is the picture of a single state of affairs (Sect. 3.2), when it enters an inference it behaves in the usual way; the 'special case' of 'p and not p' plays the role of a normal atomic sentence.

${ }^{46}$ I owe a debt of gratitude to a number of friends who have made important contributions to the development of the research here presented. The greatest intellectual debt is owed to Elena Ficara and JC Beall, whose work on conjunction in Hegel's treatment of contradictions has formerly inspired the 'two gaps for one glut' idea. Many friends have read and commented on various versions of this paper, above all: Achille Varzi, Graham Priest, Franz Berto, and Matteo Plebani. I am enormously grateful to Synthese's anonymous referees: their sometimes harsh but justified criticism gave extremely relevant insights to improve not only the article but also the theory presented within. 
Beall, J. C. (2006a). Negation's holiday: Aspectival dialetheism. DeVidi and Kenyon (Eds.), 2006, 169-192.

Beall, J. C. (2007a). Prolegomenon to future revenge. In Beall (Ed.), 2007b, 1-30

Beall, J. C. (Ed.). (2007b). Revenge of the liar. New essays on the paradox. Oxford University Press.

Beall, J. C. (2009). Spandrels of truth. Oxford University Press.

Beall, J. C. (2014). End of inclosure. Mind, 123(491), 829-849.

Beall, J. C. (2019). Transparent truth as logical property. Published online (entailments.net)

Beall, J. C., \& Armour-Garb, B. (2005). Deflationism and paradox. Oxford University Press.

Beall, J. C., \& Ficara, E. (2014). Hegelian contradiction and Hegelian conjunction (manuscript)

Beall, J. C., Glanzberg, M., \& Ripley, D. (2017). Liar paradox. In: E. N. Zalta (Ed.), Stanford encyclopedia of philosophy, fall 2017 Edition. https://plato.stanford.edu/archives/fall2017/entries/liar-parad ox/

Beall, J. C., Glanzberg, M., \& Ripley, D. (2018). Formal theories of truth. Oxford University Press.

Beebee, H., \& Dodd, J. (Eds.). (2005). Truthmakers. The contemporary debate. Oxford University Press.

Belnap, N. D., Jr. (1977). A useful four-valued logic. In J. M. Dunn \& G. Epstein (Eds.), Modern uses of multiple-valued logics, 1977, 5-37. Reidel.

Berto, F. (2007). How to sell a contradiction. The logic and metaphysics of inconsistency. King's College.

Berto, F. (2008). Adynaton and material exclusion. Australasian Journal of Philosophy, 86(2), 165-190.

Cargile, J. (1969). The sorites paradox. British Journal for the Philosophy of Science, 20(3), 193-202.

Cobreros, P. (2013). Vagueness: Subvaluationism. Philosophy Compass, 8, 472-483.

Cobreros, P., Egré, P., Ripley, D., \& van Rooj, R. (2012). Tolerant, classical, strict. Journal of Philosophical Logic, 41, 347-385.

Cobreros, P., Egré, P., Ripley, D., \& van Rooj, R. (2015). Pragmatic interpretations of vague expressions: strongest meaning and non-monotonic consequence. Journal of Philosophical Logic, 44, 375-393.

Cook, R. A. (2007). Embracing revenge: On the indefinite extendibility of language. In Beall (Ed.) (2007, pp. 31-52)

d'Agostini, F. (2008). Hegel's interpretation of megarian paradoxes. In The last fumes. Nihilism and the nature of philosophical concepts (2008, pp. 203-223). Davies Group Publishers

d'Agostini, F. (2014). Paradoxes and the reality of contradictions. In E. Ficara (Ed.), Contradictions. Logic, History, Actuality. De Gruyter.

d'Agostini, F. (2019a). Misunderstandings about truth. Church, Communication and Culture., 4(3), 266-286.

d'Agostini, F. (2019b). Reducing redundancy in metaphysics. Giornale di Metafisica, Special Issue on Metametaphysics, XLI(1), 140-158.

DeVidi, D., \& Kenyon, T. (Eds.). (2006). A logical approach to philosophy. Springer.

Diogenes, L. (2018). Lives of the eminent philosophers. In J. Miller (Ed.), transl. P. Mensch. Oxford University Press

Dultilh Novaes, C. (2021). The dialogical roots of deduction: Historical, cognitive, and philosophical perspectives on reasoning. Cambridge University Press.

Dummett, M. (1993). The seas of language. Oxford University Press.

Estrada, G. L. (2017). Impossible worlds and the intensional sense of 'And.' Argumenta, 2, 227-240.

Ficara, E. (2015). Contrariety and contradiction. Hegel and the 'Berliner Aristotelismus.' Hegel-Studien, $49,39-56$.

Ficara, E. (2021). The form of truth. Hegel's philosophical logic. De Gruyter.

Field, H. (2005). Is the Liar both true and false? In Beall \& Armour-Garb (Eds.) 2005, 23-40.

Field, H. (2007). Solving the paradoxes, escaping revenge. In Beall (Ed.), 2007b, 78-144.

Field, H. (2008). Saving truth from paradox. Oxford University Press.

Fine, K. (2012). A guide to ground. In F. Correia \& B. Schneider (Eds.), Because. Cambridge University Press.

Fine, K. (2017). Truthmaker semantics. In B. Hale, C. Wright, \& A. Miller (Eds.), A companion to the philosophy of language (Vol. II). Wiley Blackwell.

Fine, K., \& Jago, M. (2017). Exact truthmaker logic. Manuscript (published on academia.edu)

Fine, K., \& Jago, M. (2019) An introduction to truthmaker semantics. Textbook (published on academia. edu)

Glanzberg, M. (Ed.). (2018). The Oxford handbook of truth. Oxford University Press.

Goldstein, L. (2000). A unified solution to some paradoxes. Proceedings of the Aristotelian Society., $100(1), 53-74$. 
Goldstein, L. (2006). Russell, Edward Lear, Plato, Zeno, Grelling, Eubulides. In J. Škilters, M. Eklund, O. Páll Jónsson, \& O. K. Wiegand (Eds.), Paradox: Logical, cognitive and communicative aspects (2006, pp. 51-68). University of Latvia.

Gupta, A. (1982). Truth and paradox. Journal of Philosophical Logic., 11, 1-60.

Gupta, A., \& Belnap, N. (1993). The revision theory of truth. CSLI.

Havas, K. (1981). Some remarks on an attempt at formalizing dialectical logic. Studies in Soviet Thought, 22(4), 257-264.

Havas, K. (1983). Thought, language and reality in logic, Budapest: Akadémiai Kiado (references are to the 1992 English translation).

Hintikka, J. (2007). Socratic epistemology. Cambridge University Press.

Humberstone, L. (2011). The Connectives. MIT Press.

Jago, M. (2018). What truth is. Oxford University Press.

Jago, M. (2020). Truthmaker semantics for relevant logic. Journal of Philosophical Logic, 2020(49), 681-702.

Jaśkowski, S. (1948). Propositional calculus for contradictory deductive systems. Engl. Tr. in Studia Logica, 24(1969), 143-157.

Jaśkowski, S. (1999). On the discussive conjunction in the propositional calculus for inconsistent deductive systems. Logic and Logical Philosophy, 7, 57-59.

Kabay, P. (2010). On the plenitude of truth. A defense of trivialism. Lambert Academic Publishing.

Leitgeb, H. (2014). A way out the preface paradox? Analysis, 74(1), 11-15.

Leitgeb, H. (2019). HYPE: A System of hyperintensional logic (with an application to semantic paradoxes). Journal of Philosophical Logic, 48(2), 305-405.

Lewis, D. K. (1982). Logic for equivocators. Reprinted in Lewis, 1998, 97-110.

Lewis, D. K. (1998). Papers in philosophical logic. Cambridge University Press.

Mares, E. D. (2004). Relevance logic. A philosophical interpretation. Cambridge University Press.

Mares, E. (2012). Relevance and conjunction. Journal of Logic and Computation, 22(1), 7-21.

Mares, E., \& Meyer, J.-J. (2001). Relevant logics. In L. Goble (Ed.), Philosophical logic (pp. 280-308). Blackwell.

Marques, T. (2014). Doxastic disagreement. Erkenntnis, 79(S1), 121-142.

Marsili, N. (2018). Truth and assertion: rules versus norms. Analysis, 78(4), 638-648.

Martin, B. (2014). The logical and philosophical foundations for the possibility of true contradictions. Doctoral dissertation, University College, London

Martin, B. (2015). Dialetheism and the impossibility of the world. Australasian Journal of Philosophy, 93(1), 61-75.

Murzi, J., \& Carrara, M. (2015). Denial and disagreement. Topoi, 34(2015), 109-119.

Oliver, A., \& Smiley, T. (2013). Plural logic. Oxford University Press.

Plumwood, V. (1970). Some false laws of logic. Unpublished paper, n. 1862 of the legacy

Priest, G. (1995). Beyond the limits of thought. Cambridge University Press.

Priest, G. (2001). Paraconsistent belief revision. Theoria, 67, 214-228.

Priest, G. (2002a). Paraconsistent logic. In D. Gabbay \& F. Guenthner (Eds.), Handbook of philosophical logic (pp. 287-393). Kluwer Academic.

Priest, G. (2002b). Logicians setting together contradictories: A perspective on relevance, paraconsistency, and dialetheism. In D. Jacquette (Ed.), 2002. A companion to philosophical logic (pp. 651664). Blackwell.

Priest, G. (2003). A site for sorites. In Beall (Ed.), 2003, 9-23.

Priest, G. (2006). Doubt truth to be a liar. Oxford University Press.

Priest, G. (1987²). In contradiction, New edition (2006). Oxford University Press

Priest, G. (2007). Paraconsistency and dialetheism. In D. Gabbay \& J. Woods (Eds.), The many valued and nonmonotonic turn in logic. Vol. 8 of Handbook of the history of logic (pp. 129-204).

Priest, G. (2008). An introduction to non-classical logic. From if to is. Cambridge University Press.

Priest, G. (2014). One. Oxford University Press.

Priest, G. (2015). Fusion and confusion. Topoi, 34, 55-61.

Priest, G., Beall, J. C., \& Armour-Garb, B. (Eds.). (2004). The law of non-contradiction. New philosophical essays. Oxford University Press.

Priest, G., \& Routley, R. (1989). Systems of paraconsistent logic. In Priest, Routley and Norman, 1989, 151-186.

Priest, G., Routley, R., \& Norman, J. (1989). Paraconsistent logics. Philosophia Vlg. 
Ramirez, E. (2017). The many faces of antiphasis. In The philosophy of contra-classical logics conference, UNAM, 4 Sept. 2017 (forthcoming paper)

Read, S. (2012). Relevant logic. A philosophical examination of inference. Blackwell.

Rescher, N., \& Brandom, R. (1980). The logic of inconsistency. A study in non-standard possible worlds semantic and ontology. Blackwell.

Ripley, D. (2011). Contradictions at the borders. In R. Neuwen \& R. van Rooj (Eds.), Vagueness in communication (pp. 169-188). Springer.

Ripley, D. (2015). Paraconsistent logic. Journal of Philosophical Logic., 44(6), 771-780.

Rodriguez-Pereyra, G. (2005). Why truthmakers? In Beebee \& Dodd (Eds.) (pp. 17-31)

Rodriguez-Pereyra, G. (2006). Truthmaking, entailment, and the conjunction thesis. Mind, 115, 957-982.

Rodriguez-Pereyra, G. (2009). The disjunction and conjunction theses. Mind, 118(470), 428-442.

Sainsbury, M. (1995). Paradoxes (3rd ed., 2009). Oxford University Press.

Saul, J. (2012). Lying misleading and what is said. An exploration in philosophy of language and ethics. Oxford University Press.

Scharp, K. (2013). Replacing truth. Oxford University Press.

Schein, B. (2017). And. conjunction reduction redux. MIT Press.

Serchuck, P., Hargreaves, I., \& Zach, R. (2011). Vagueness, logic and use: Four experimental studies on vagueness. Mind and Language, 26, 540-573.

Shapiro, S. (2004). Simple truth, contradiction, and consistency. In Priest et al. (Eds.) (2004, pp 336-354).

Simmons, K. (1993). Universality and the liar. An essay on truth and the diagonal argument. Oxford University Press.

Smilansky, S. (1994). Fortunate misfortune. Ratio, 7, 153-163.

Smilansky, S. (2007). Ten moral paradoxes. Oxford University Press.

Smith, M. (2016). Between probability and certainty. Clarendon.

Sorensen, R. A. (2003a). A brief history of the paradox. Oxford University Press.

Sorensen, R. A. (2003b). Paradoxes of rationality. In A. Mele (Ed.), The handbook of rationality (pp. 257-275). Oxford University Press.

Sorensen, R. A. (2018a). Epistemic paradoxes. In E. N. Zalta (Ed.), Stanford encyclopedia of philosophy. https://plato.stanford.edu/archives/sum2018/entries/epistemic-paradoxes/

Sorensen, R. A. (2018b). Semantic paradoxes: A psychohistory of self-defeat. In: Glanzberg (Ed.) (2018)

Tallant, J. (2018). Truth and the world. Routledge.

Tarski, A. (1944). The semantic conception of truth. Philosophy and Phenomenological Research, 4, $341-376$.

Varzi, A. (2004). Conjunction and contradiction. In Priest, Beall, \& Armour-Garb (Eds.), 2004, 93-110.

Yablo, S. (2014). Aboutness. Oxford University Press.

Publisher's note Springer Nature remains neutral with regard to jurisdictional claims in published maps and institutional affiliations. 